\title{
Über das Husten
}

\section{Eberhard Wolff}

Prof. Dr. rer. soc., Redaktor Kultur, Geschichte, Gesellschaft

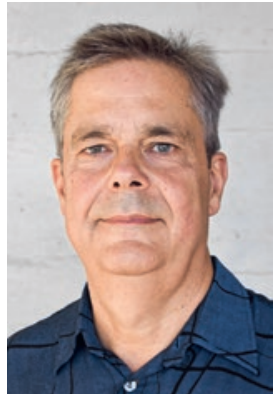

Literatur

1 Stillich S. Wer hustet, stirbt. Der Spiegel online. 16.9.2009.

2 Siehe z.B.: «Raucherhusten-Blues» von Insterburg \& Co, 1973.

3 Ehrensperger A. AtemWege. Erkundungen zu Luftverschmutzung, Atemnot und Achtsamkeit. Zürich: Chronos; 2020.

4 Vogt W. Husten. Wahrscheinliche und unwahrscheinliche Geschichten Zürich/Frauenfeld: Nage \& Kimche; 1990 (1965).

eberhard.wolff[at]saez.ch
Unser Kater heisst Herbie. Ich reagiere allergisch auf ihn. Mein deshalb mässiger Reizhusten störte bislang nur wenig. Als ich aber in diesem Frühjahr auf dem Weg zum Bäcker etwas husten musste, wechselte ein entgegenkommender Mitmensch misstrauisch die Strassenseite. Eine Lepraklapper hätte im Mittelalter keine effizienteren Dienste leisten können als mein Reizhusten unlängst.

Corona hat das Image des Hustens grundsätzlich verändert. Und die mit ihm verbundenen Gefühle. Als primäres Corona-Symptom wurde er fast über Nacht vom Alltagsphänomen, etwa bei Erkältungen, zum Auslöser von Furcht und Schrecken.

Die famose Fähigkeit unserer Körper, Störendes mit Luftstössen aus dem Atmungsapparat herauszubefördern, war immer schon eine ebenso verbreitete wie vielgestaltige körperliche Erscheinungsform. An ihrem einen Ende steht die medizinische Belanglosigkeit («Hüstel!»). An ihrem anderen ist der Husten ein Bote des nahen Todes. Ein altes Erzählmotiv, das heute als Filmklischee lebt: «Wer hustet, stirbt» [1].

Als das Kranksein noch weniger in genau angeschriebenen Schubladen lebte, war das Husten eher ein Indiz allgemeinen "Siechtums». Mit der medizinischen Moderne stachen dann einzelne zugeordnete Hustenformen deutlicher aus der Masse heraus und prägten das jeweilige allgemeine Bild des Hustens. Man könnte sie die «Leithusten» ihrer Zeiten und Orte nennen.

Etwa wenn Keuchhusten epidemisch auftrat. Die fast erstickenden Kinder lösten mit ihrem unaufhörlichen und quälenden Husten Verzweiflung, Angst und Mitleid aus. Ähnlich heute bei der Cystischen Fibrose.

Wo intensiv Bergbau betrieben wurde, gaben die verstaubte Bergmannslungen den Leithusten vor. Er erweckte nicht nur Mitleid, sondern forderte auch den Respekt vor einem herausfordernden Arbeitsleben unter Tage. Ein männlicher Husten.

Im schwindsüchtigen Husten der Gründerzeit liefen viele Hustenimages zusammen. Thomas Manns Roman Der Zauberberg (geschrieben zwischen 1913 und 1924) öffnet im Tuberkulose-Sanatorium eine Palette von der «Vergnüglichkeit» des Hustens der geschwätzigen Frau Stöhr bis zu den «schlimmsten Hustenanfällen» der jungen Leila Gerngross auf dem Sterbebett.
Das mit der Tuberkulose gross gewordene bakteriologische Zeitalter fügte dem Husten das hervorstechende Image einer Gefahr für den Nebenmenschen an. Der Husten verbündete sich mit der Ansteckungsangst. Gesundheitserzieherische Plakate visualisierten den Husten als Vektor und machten ihn zur Frage individueller Verantwortung und Schuld, auch bei der Spanischen Grippe.

Als die Infektionskrankheiten in den 1970er Jahren zumindest in der westlichen Welt - besiegt schienen, drängte sich der Raucherhusten [2] als Leithusten in den Vordergrund. Der war lästig, störend und nicht zuletzt ein Ekelfaktor. Als dem Tabak dann der Krieg erklärt wurde, geriet der Raucherhusten zum Massstab von Sucht, Gesundheitsmoral und Selbstkontrolle. Gegen Ende des letzten Jahrhunderts wurden verschiedene pulmonale Phänomene unter dem neuen Krankheitsbild des COPD gefasst. Da auch die Luftverschmutzung [3] zu ihren Ursachen zählt, verlagerte sich die Schuld für den Husten wieder ein Stück vom Einzelnen auf die moderne Industriegesellschaft.

Daneben blieb der Husten immer auch banal. Als der eigensinnige Berner Schriftsteller und Psychiater Walter Vogt 1965 seine Kurzgeschichte Husten schrieb, in der sich der höhere Beamte Felix Wieder hoffnungslos im Medizinsystem verstrickt und schliesslich stirbt, wählte Vogt nicht zufällig dieses harmlose Symptom als Ausgangspunkt [4].

Heute ist «harmlos» Geschichte. In coronischen Zeiten löst Husten wieder unmittelbare Angst vor individueller Ansteckung aus. Und mehr noch. In ihm schwingt der Vorwurf der kollektiven Ansteckung, des epidemischen Superspreadings, mit. Husten als Generalverdacht sozusagen.

"Mama, darf ich jetzt nicht mehr husten?», fragte neulich auf der Strasse ein Kind. Der Husten verschwindet so zumindest teil- und zeitweise aus der Öffentlichkeit.

Im Hallenbad huste ich neuerdings konsequent unter Wasser. Ein Kollege von mir ist auf den gleichen Trick gekommen. Die Jakobsmuscheln machen es schliesslich auch so.

Solange der imaginierte Coronahusten der Leithusten ist, werde ich das Unterwasserhusten praktizieren. Felix Wieder hätte es genauso machen sollen. 